\title{
Editorial
}

\section{Dye-Sensitized Solar Cells: From Materials to Devices}

\author{
Tianxin Wei ${ }^{1}$ and Theodoros Dimopoulos ${ }^{2}$ \\ ${ }^{1}$ School of Chemistry, Beijing Institute of Technology, Beijing 100081, China \\ ${ }^{2}$ Energy Department, Electric Energy Systems, Austrian Institute of Technology AIT, 1210 Vienna, Austria
}

Correspondence should be addressed to Tianxin Wei; txwei@bit.edu.cn

and Theodoros Dimopoulos; theodoros.dimopoulos@ait.ac.at

Received 29 August 2013; Accepted 29 August 2013

Copyright (C) 2013 T. Wei and T. Dimopoulos. This is an open access article distributed under the Creative Commons Attribution License, which permits unrestricted use, distribution, and reproduction in any medium, provided the original work is properly cited.

The need to replace fossil fuels with renewable and sustainable energy sources is more exigent than ever, in order to reduce $\mathrm{CO}_{2}$ emissions causing climatic change and guarantee the further development of mankind in harmony with our natural environment. Photovoltaics (PV) is considered as one of the most reliable platforms for green energy production. To convert sunlight into electricity, the majority of PV technologies rely on semiconductor $\mathrm{p}-\mathrm{n}$ junctions. An alternative attractive strategy is the development of photoelectrochemical solar cells, the function of which is based on the photosensitization process.

In photosensitization, a molecule called photosensitizer (or simply sensitizer), absorbs light, is lifted to an excited electronic state, and transfers the charge to an acceptor, giving rise to a chain of chemical reactions. The sensitizer usually returns to its original state by receiving electrons from another source. In natural photosynthesis, plants use the chlorophyll pigment in the chloroplasts as sensitizer that captures sunlight and donates electrons to a series of molecular intermediates, resulting in the production of chemical energy.

In technology, photosensitization was firstly demonstrated in 1873 by Hermann Wilhelm Vogel [1], who mixed dyes of different colors in photographic emulsions to render silver halide photographic plates sensitive to different parts of the light spectrum. The underlying physical mechanism is the injection of electrons from the photoexcited dye to the silver halide, with the subsequent formation of metallic silver.

In the 1960s and 70s, semiconductor electrodes were sensitized with organic pigments in electrochemical cells, converting the electronic photoexcitation of the pigment into electric energy $[2,3]$, albeit with very low efficiency.
Efforts towards electricity production led to a breakthrough in 1991, when the first dye-sensitized solar cell (DSSC) with photovoltaic properties competitive to the conventional silicon-based technology was presented by B. O'Regan and M. Grätzel [4]. Their success relied on the use of a mesoporous $\mathrm{TiO}_{2}$ film with a very large internal surface area for sensitization and the employment of a Ru-based, metallorganic dye with optimized spectral characteristics for light harvesting. The operation principle of the DSSC is based on the injection of electrons from the photoexcited dye to the $\mathrm{TiO}_{2}$, the transport of electrons towards the conducting glass substrate, and the regeneration of the dye by electron transfer from a redox electrolyte, which is then reduced at the counter electrode.

Since this ground-breaking work, a series of energy conversion efficiency records were marked, bringing the current state of the art close to $15 \%$, through the employment of newly developed perovskite dyes and sensitization recipes [5]. This efficiency is amongst the highest for solution processed PV. Research in all material components of the DSSC, that is, dyes, nanostructured electrodes, electrolytes, and encapsulation, is intensified continuously, bringing the DSSC very close to widespread application.

Sensitizer development is an important issue, targeting materials which combine absorption matched to the solar spectrum, easy chemisorption onto the semiconductor surface, efficient electron injection into the semiconductor's conduction band, low cost, and environmental sustainability. In particular regarding the last points, natural pigments, stemming from plants, and flowers, could provide a viable alternative to expensive synthetic dyes, although the maximum 
achieved efficiency of $1.7 \%$ [6] is still very low. In this special issue of the Journal of Photoenergy, a number of papers deal with the sensitizer, covering both computational studies of their molecular structure and properties and experimental investigations of natural and synthetic dyes employed in solar cells.

Another important aspect of the DSSC is the nanostructured semiconductor electrode, which has to provide the necessary large internal surface area, as well as promoting easy electron transfer from the dye and efficient electron transport. This special issue contains advances in the development of nanostructured semiconductor photoanodes, such as $\mathrm{TiO}_{2}$ nanocrystalline films and nanotube arrays or $\mathrm{ZnO}$ nanostructures. Last but not the least, investigations on the interaction of the redox electrolyte with the other DSSC components are included.

We hope that the reader will find in this issue many interesting information on the materials and DSSC device development.

Tianxin Wei Theodoros Dimopoulos

\section{References}

[1] W. West, "Proceedings of vogel centennial symposium," Photographic Science and Engineering, pp. 18-35, 1974.

[2] H. Gerischer and H. Tributsch, "Elektrochemische Untersuchungen über den Mechanismus der Sensibilisierung und Übersensibilisierung an $\mathrm{ZnO}$-Einkristallen," Berichte der Bunsengesellschaft für Physikalische Chemie, vol. 73, pp. 251-260, 1969.

[3] H. Tributsch and M. Calvin, "Electrochemistry of excited molecules: photoelectrochemical reactions of chlorophylls," Photochemistry and Photobiology, vol. 14, pp. 95-112, 1971.

[4] B. O’Regan and M. Grätzel, "A low-cost, high-efficiency solar cell based on dye-sensitized colloidal $\mathrm{TiO}_{2}$ films," Nature, vol. 353, no. 6346, pp. 737-740, 1991.

[5] J. Burschka, N. Pellet, S. J. Moon et al., "Sequential deposition as a route to high-performance perovskite-sensitized solar cells," Nature, vol. 499, no. 7458, pp. 316-319, 2013.

[6] G. Calogero, G. Di Marco, S. Cazzanti et al., "Efficient dyesensitized solar cells using red turnip and purple wild Sicilian prickly pear fruits," International Journal of Molecular Sciences, vol. 11, no. 1, pp. 254-267, 2010. 

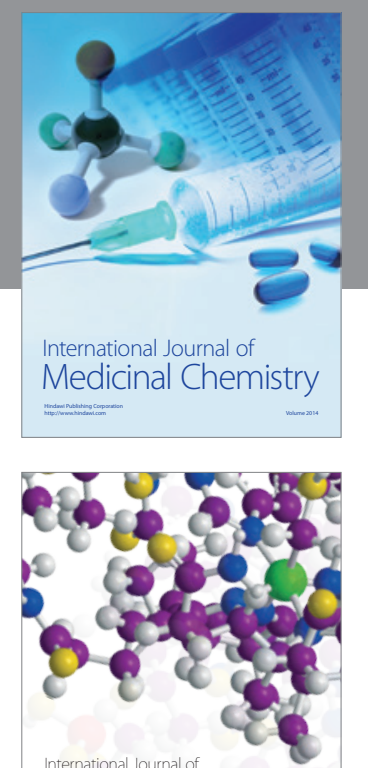

\section{Carbohydrate} Chemistry

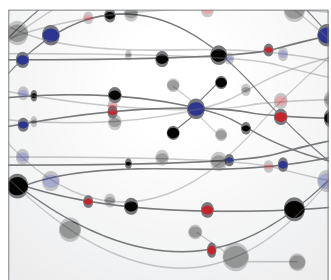

The Scientific World Journal
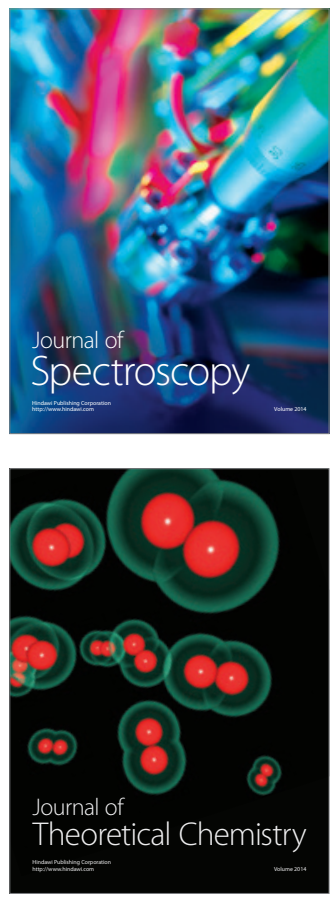
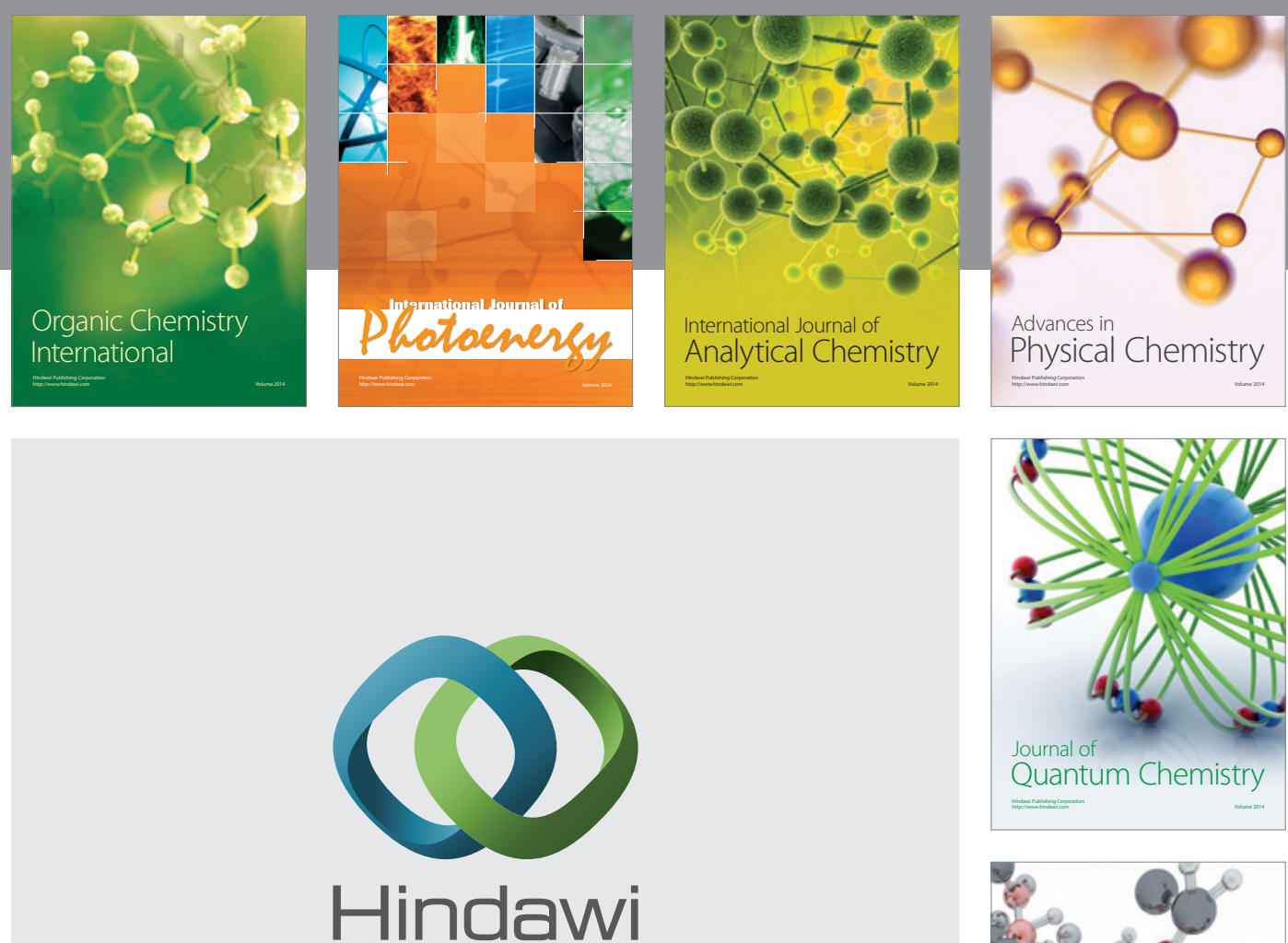

Submit your manuscripts at

http://www.hindawi.com

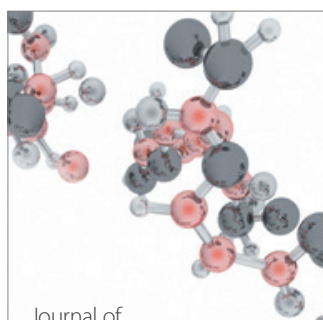

Analytical Methods

in Chemistry

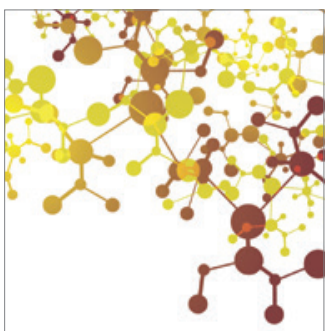

Journal of

Applied Chemistry

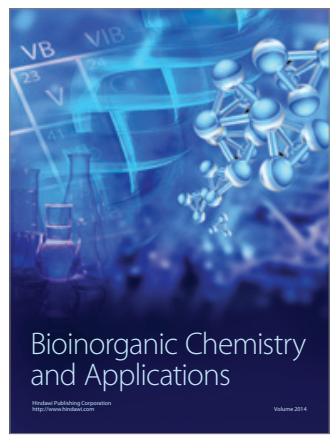

Inorganic Chemistry
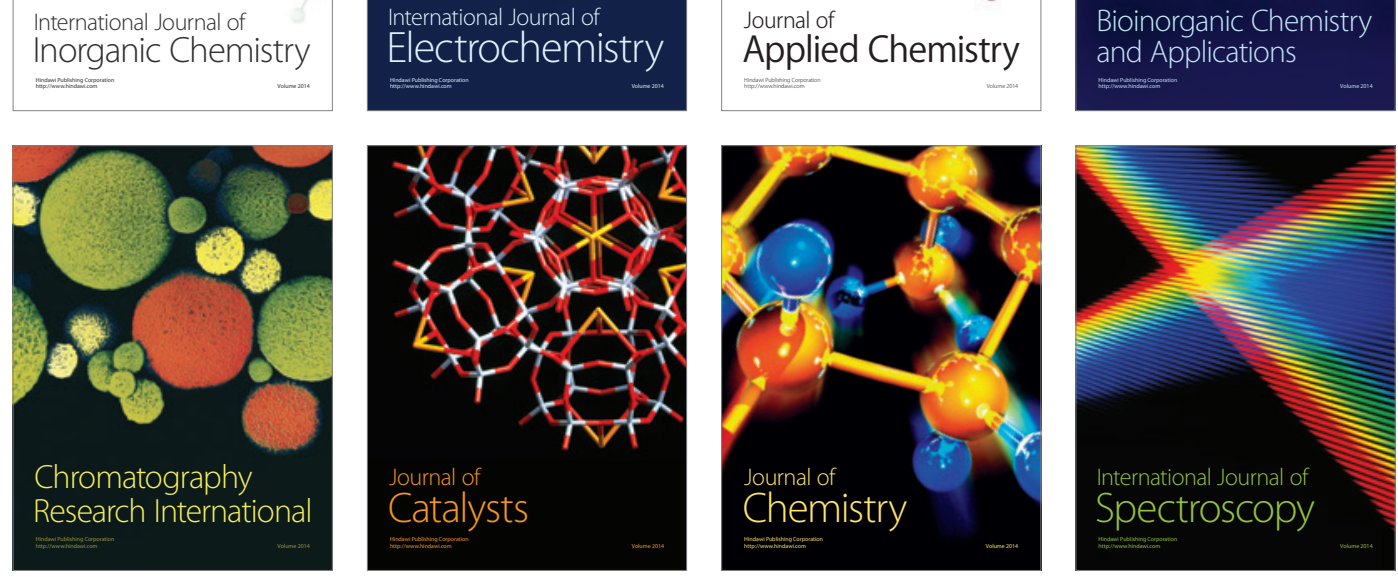